\title{
Chapter 17 \\ Protective Intestinal Effects of Pituitary Adenylate Cyclase Activating Polypeptide
}

\author{
Gabriella Horvath, Anita Illes, Markus M. Heimesaat, Attila Bardosi, \\ Sebastian Bardosi, Andrea Tamas, Balazs D. Fulop, Balazs Opper, \\ Jozsef Nemeth, Andrea Ferencz, and Dora Reglodi
}

\begin{abstract}
Pituitary adenylate cyclase activating polypeptide (PACAP) is an endogenous neuropeptide widely distributed throughout the body, including the gastrointestinal tract. Several effects have been described in human and animal intestines. Among others, PACAP influences secretion of intestinal glands, blood flow, and smooth muscle contraction. PACAP is a well-known cytoprotective peptide with strong anti-apoptotic, anti-inflammatory, and antioxidant effects. The present review gives an overview of the intestinal protective actions of this neuropeptide. Exogenous PACAP treatment was protective in a rat model of small bowel autotransplantation. Radioimmunoassay (RIA) analysis of the intestinal tissue
\end{abstract}

Andrea Ferencz and Dora Reglodi contributed equally

G. Horvath $\bullet$ A. Tamas $\bullet$ D.B. Fulop $\bullet$ B. Opper $\bullet$ D. Reglodi $(\bowtie)$

Department of Anatomy, MTA-PTE “Lendulet” PACAP Research Group, University of Pecs, Pecs, Hungary

e-mail: dora.reglodi@aok.pte.hu
A. Illes
Department of Anatomy, MTA-PTE “Lendulet” PACAP Research Group, University of Pecs, Pecs, Hungary
Department of Internal Medicine, University of Pecs, Pecs, Hungary
M.M. Heimesaat
Department of Microbiology and Hygiene, Charite-University Medicine, Berlin, Germany
A. Bardosi • S. Bardosi
Jakob Henle Institute for Pathology and Neuropathology, Limbach Group,
Heidelberg, Germany

\section{J. Nemeth}
Department of Pharmacology and Pharmacotherapy, University of Debrecen,
Debrecen, Hungary
A. Ferencz
Department of Surgical Research and Techniques, Semmelweis University,
Budapest, Hungary

D. Reglodi, A. Tamas (eds.), Pituitary Adenylate Cyclase Activating

Polypeptide - PACAP, Current Topics in Neurotoxicity 11,

DOI 10.1007/978-3-319-35135-3_17 
showed that endogenous PACAP levels gradually decreased with longer-lasting ischemic periods, prevented by PACAP addition. PACAP counteracted deleterious effects of ischemia on oxidative stress markers and cytokines. Another series of experiments investigated the role of endogenous PACAP in intestines in PACAP knockout (KO) mice. Warm ischemia-reperfusion injury and cold preservation models showed that the lack of PACAP caused a higher vulnerability against ischemic periods. Changes were more severe in PACAP KO mice at all examined time points. This finding was supported by increased levels of oxidative stress markers and decreased expression of antioxidant molecules. PACAP was proven to be protective not only in ischemic but also in inflammatory bowel diseases. A recent study showed that PACAP treatment prolonged survival of Toxoplasma gondii infected mice suffering from acute ileitis and was able to reduce the ileal expression of proinflammatory cytokines. We completed the present review with recent clinical results obtained in patients suffering from inflammatory bowel diseases. It was found that PACAP levels were altered depending on the activity, type of the disease, and antibiotic therapy, suggesting its probable role in inflammatory events of the intestine.

\section{Keywords Ileitis $\bullet$ Intestinal ischemia $\bullet$ Crohn's disease $\bullet$ Colitis $\bullet$ PACAP}

\section{Introduction}

Pituitary adenylate cyclase activating polypeptide (PACAP) is a widely recognized neuroprotective peptide. The neuroprotective actions of PACAP were soon recognized after its isolation from ovine hypothalami in 1989 [1, 2]. Subsequent studies showed that the occurrence of PACAP is widespread, it can be found in all organ systems, not only in the nervous system and so its general anti-apoptotic, antioxidant, and anti-inflammatory effects can be observed in numerous different organs and tissues besides the nervous system. The neuroprotective and general cytoprotective effects of PACAP have been reviewed in the recent years, and several aspects of this action can be found in other chapters of this book [2-5].

PACAP is also present in the gastrointestinal system where it exerts several actions. PACAP influences motility of the intestinal wall [6], an action phylogenetically well conserved [7], and it also regulates sphincter muscles [8-10]. PACAP acts on intestinal secretion, among others, it has been shown that PACAP stimulates secretion of growth factors, like brain-derived neurotrophic factor (BDNF) from intestinal smooth muscle cells [11]; furthermore, it inhibits pacemaker activity of interstitial cells of Cajal [12]. In the present review we briefly summarize protective actions of PACAP in the intestinal system, mainly in ischemic and inflammatory bowel disease models and give a brief summary of studies done in PACAP gene deficient mice. We also briefly review pathological findings on PACAP and/or receptor expression in both animal models and in human biopsies and we report on our recent findings in human samples from patients with inflammatory bowel disease. 


\section{Effects of Exogenous PACAP in Small Bowel Ischemia-Reperfusion Injury in Rats}

Intestinal warm ischemia-reperfusion (I/R) is associated with high morbidity and mortality in some critical clinical settings, such as hemorrhagic shock, strangulation, obstruction, cardiovascular surgery, and severe trauma. Several factors are involved in the cascade of events resulting in intestinal death and critical condition of the patient following mesenteric infarction. These include production of reactive oxygen species leading to oxidative stress, inflammation, and finally tissue necrosis with septic signs $[13,14]$.

PACAP has been shown to protect against ischemic injuries in several tissues. The first studies showing the neuroprotective effects of PACAP investigated these effects in global and focal brain ischemia $[15,16]$. Subsequently, numerous other studies confirmed that PACAP exerts strong protective effects in neuronal ischemic injuries [2, 17-20]. PACAP's efficacy in protecting tissues against ischemic lesions has become evident in the retina [21-23] and in peripheral tissues, such as liver [24], kidney [25-28], and heart [29]. Thus, it is not surprising that PACAP is also protective in intestinal I/R injury. In the following sections, we give a brief overview of our studies regarding the effects of exogenously administered PACAP in small intestinal ischemia, summarized in Fig. 17.1.

Our first studies showed that PACAP is protective in a rat model of small bowel autotransplantation, a cold ischemia injury model [30-32]. Small bowel was resected and grafts were preserved in University of Wisconsin solution, as commercially available, standard solution during transplantation, with or without additional PACAP. Grafts were autotransplanted after 1, 2, 3, or $6 \mathrm{~h}$ with a reperfusion lasting $3 \mathrm{~h}$, a procedure called cold preservation injury. Radioimmunoassay (RIA) analysis of the intestinal tissue showed that endogenous PACAP levels gradually decreased with longer-lasting warm and cold ischemic periods, but tissue levels of both PACAP38 and PACAP27 remained higher when PACAP38 was added to the solution $[30,33]$. Histological analysis showed that cold ischemia led to a destruction of the mucous, submucous, and muscularis layers, further deteriorated by the end of the reperfusion. PACAP protected the intestinal structure: a better preserved mucous layer and crypt morphology could be observed. These results clearly showed that PACAP was protective in intestinal cold I/R injury [30, 31]. They also demonstrated that adding PACAP to the preservation solution did not increase lipid peroxidation and prevented the reduction of endogenous scavenger capacity.

Studying the mechanism of action, we used biochemical assays to measure the oxidative stress markers and antioxidant enzyme levels, and molecular biological methods to study the expression of apoptotic signaling. Biochemical assays from the samples obtained after $3 \mathrm{~h}$ of reperfusion following 1, 2, 3, and $6 \mathrm{~h}$ of cold intestinal ischemia showed that malondialdehyde (MDA), an oxidative stress marker, gradually increased with the duration of the ischemia, while this increase was markedly less in the PACAP-treated groups. In contrast, levels of the endogenous scavenger molecule, reduced glutathione (GSH), showed a significant decrease with long-lasting I/R in the 


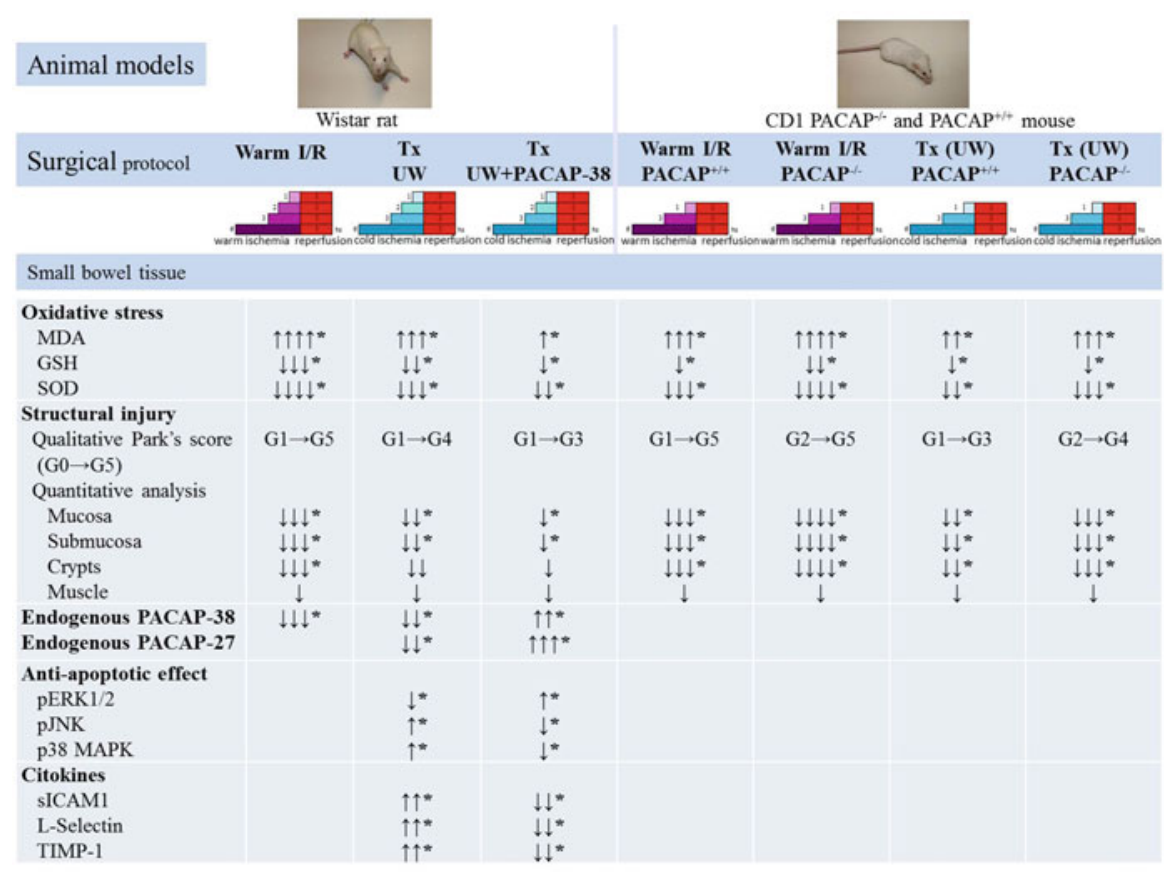

Fig. 17.1 Cytoprotective, anti-apoptotic, and anti-inflammatory effect of PACAP in intestinal warm ischemia-reperfusion (I/R) and transplantation (Tx)/cold ischemia animal models. Warm ischemia and cold storage in University of Wisconsin (UW) preservation solution lasted 1, 2, 3, or $6 \mathrm{~h}$, while reperfusion took $3 \mathrm{~h}$ in each groups. According to Park's classification tissue injury was analyzed from grade zero (control) to the highest grade of injury (grade 5: G5). (PACAP ${ }^{+/+}$PACAP wild type mice, $P A C A P^{-/-}$PACAP knockout mice, $M D A$ malondialdehyde, $G S H$ reduced glutathione, $S O D$ superoxide dismutase, $p E R K 1 / 2$ phosphorylated-ERK1/2, $p J N K$ phosphorylated-Jun-Nterminal kinase, $p 38$ MAPK p38 Mitogen Activated Protein Kinase, sICAM1 soluble Intercellular Adhesion Molecule-1, TIMP-1 Tissue Inhibitor of MetalloProteinase-1)

control groups. In PACAP-treated groups, GSH levels were near baseline values and the level of this endogenous scavenger was higher in all PACAP-treated groups than in the ischemic control groups. A dramatic decrease was observed in activity of antioxidant enzyme: superoxide dismutase (SOD) in the control ischemic groups. In PACAP-treated groups only a slight decrease could be observed.

In another study, we examined changes of cytokine expression in the intestinal tissue after different ischemic periods in University of Wisconsin solution with or without additional PACAP using cytokine array and Luminex multiplex immunoassay [33]. It was found that the cold ischemia-induced changes in some cytokines could be ameliorated by PACAP. Namely, elevations in expression level of the sICAM (CD54) and L-selectin (CD62L/LECAM-1) regulated upon activation could be decreased by PACAP treatment, similarly to a tendency observed in renal ischemic injury [25]. These adhesion molecules are known to be involved in crosstalk between immune cells and endothelial cells, and their overexpression can lead to microvascular dysfunction and reperfusion damage. PACAP led to a slight reduction 
also in RANTES levels and a significant decrease of the strongly induced TIMP levels [33]. Studying the mitogen activated protein (MAP) kinase phosphorylation, we found that phosphorylated ERK $1 / 2$ levels gradually decreased with the ischemic time, while JNK1/2 and p38 MAP kinase phosphorylation increased. These changes were counteracted by addition of PACAP in the preservation solution [32].

Altogether, these studies showed that PACAP is protective in intestinal I/R injury partly through increasing the antioxidant status of the intestinal tissue, via antiinflammatory actions and via anti-apoptotic signaling. This combination of antiapoptotic, anti-oxidant, and anti-inflammatory actions of PACAP have been confirmed by several other studies. One of the best-known protective effects of PACAP is its anti-apoptotic effect [34], which has been extensively studied in the nervous system [35-37], sensory organs like inner ear [38] and retina [39] and has also been shown in peripheral organ lesions, such as in diabetic nephropathy [40], and in oxidative stressinduced cardiomyocyte injury [41, 42].

The antioxidant efficacy of PACAP has also been described in other studies. Miyamoto et al. [43] showed that PACAP suppressed cortical damage in mice with traumatic brain injury by enhancing antioxidant activity. In diabetic nephropathy, Banki et al. [40] showed that PACAP treatment increased glutathione levels. PACAP also stimulated glutathione formation, and blocked $\mathrm{H}_{2} \mathrm{O}_{2}$-evoked reactive oxygen species (ROS) accumulation and glutathione content reduction in oxidative stressinduced astroglial injury [44]. In kidney ischemia-reperfusion, similar changes were observed: PACAP treatment decreased MDA levels while increased GSH levels [45]. These studies suggest that PACAP has anti-oxidant effects via indirect action of mechanism, through stimulating endogenous antioxidant capacity. This hypothesis is also supported by the observation that direct scavenging action of PACAP can only be observed at very high (micromolar) concentrations of the peptide [46].

The anti-inflammatory actions of PACAP have been more widely investigated. It has been shown that the anti-inflammatory effects of the peptide are partially mediated via suppressing chemokine/cytokine production [47]. PACAP plays an important regulatory role in the immune system, a function reviewed several times by different groups $[48,49]$. The role of PACAP in cytokine and chemokine expression has been investigated in the nervous system as well as in peripheral organs. Microglial cytokine and chemokine expression was shown to be altered by PACAP resulting in a neuroregeneration-favoring environment [50-52]. In the retina, PACAP increased anti-inflammatory cytokine expression [53]. Furthermore, PACAP led to an anti-inflammatory cytokine balance in kidney ischemia [25], in diabetic nephropathy model [54] and in retinal ischemia [55].

\section{Small Intestinal Ischemic Injury in PACAP Knockout (KO) Mice}

To answer the question of whether the intestinal protective action of PACAP can also be observed endogenously, we studied the results of intestinal I/R in PACAP KO mice, summarized in Fig. 17.1 [56-58]. No difference in the histological structure 
between young wild type and PACAP KO mice (heterozygous or homozygous) could be observed under normal circumstances (Fig. 17.2). However, in ischemic injuries, PACAP KO mice showed a higher degree of tissue injury. Cold preservation injury was studied by removing small bowel from wild type and PACAP KO mice and placing them in University of Wisconsin preservation solution for 1, 3 and $6 \mathrm{~h}$. Small bowel biopsies were collected after the ischemic periods and after laparotomy for controls. We investigated the histological structure as well as the above-mentioned oxidative stress parameters. Most severe injury was observed after $6 \mathrm{~h}$ of cold storage, as expected. After $1 \mathrm{~h}$ of cold preservation, only minor clefting with the villus epithelium adjacent to the crypts left intact. Changes were more severe in PACAP $\mathrm{KO}$ mice at all examined time points. After $6 \mathrm{~h}$, severely injured crypt appeared with denuded villi corresponding to most severe tissue injury (Grade 4), while in wild type mice this was less severe, Grade 3 injury. Quantitative histological analysis also confirmed this observation: mucosal thickness showed a more severe decrease with more prolonged ischemic times, and this decrease was more severe in PACAP KO mice. Similarly, depth of crypts and submucosal thickness were also more severely affected in PACAP-deficient mice. Measuring the parameters of oxidative stress revealed that the increase of MDA was higher, while the decrease in GSH and SOD was more pronounced in PACAP KO mice, indicating an elevated oxidative stress level in mice lacking endogenous PACAP. This corresponds well with the increased tissue injury revealed by the histological analysis [56].

We also performed warm ischemic injury in PACAP KO mice [57]. Warm ischemia was induced by occlusion of the superior mesenteric artery for 1, 3 or $6 \mathrm{~h}$. Similarly to the above studies, histological and biochemical analyses were performed. Histology showed that PACAP KO mice suffered a more severe tissue injury at all time points. For example, $3 \mathrm{~h}$ of ischemia resulted in severely injured crypts and denuded villi in $\mathrm{KO}$ mice, while this histological picture was characteristic in the wild type group only after $6 \mathrm{~h}$ of ischemic time (Fig. 17.2). Quantitative histological analysis confirmed these observations: both mucosal and submucosal thickness as well as crypt depth were more severely decreased in mice lacking endogenous PACAP. Studying the oxidative stress markers, results similar to those observed in cold ischemic injury were obtained: levels of MDA were more significantly increased in the KO groups, while those of the antioxidant SOD and GSH were more severely decreased than in the wild type animals ([57], Fig. 17.1).

These results are in agreement with the general observation that PACAP KO mice are more vulnerable to tissue injuries than wild type mice [59]. This is also true for ischemic injuries. Ohtaki and coworkers showed that PACAP KO mice have increased infarct volume in a model of stroke [60] with increased edema formation [61]. Similar results were obtained in the retina: in bilateral carotid artery occlusioninduced retinal ischemia PACAP KO mice showed increased tissue damage [62]. In peripheral organ ischemia, it has been shown that PACAP KO mice react with increased tissue injury in ischemia-reperfusion-induced kidney lesion [27, 63]. Increased inflammatory response has also been demonstrated in endotoxin-induced lung injury [64] and in contact dermatitis [65]. In the background of this increased susceptibility, a decrease in the endogenous reserve capacity, to withstand the tissue 


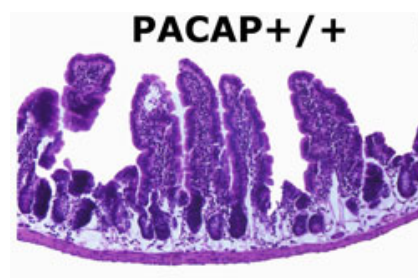

3 hs warm I/R

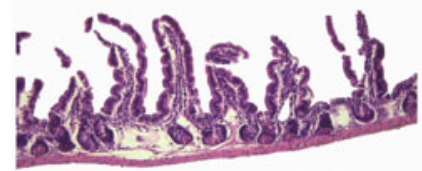

6 hs warm I/R

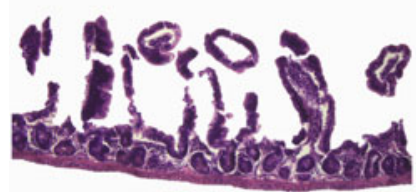

3 hs cold storage

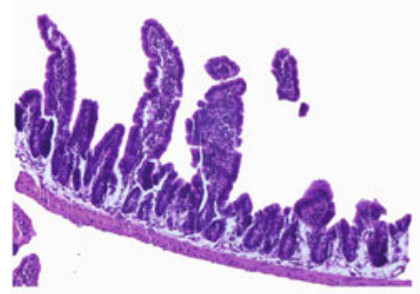

i 6 hs cold storage

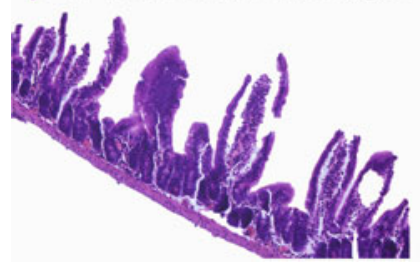

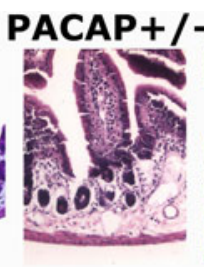

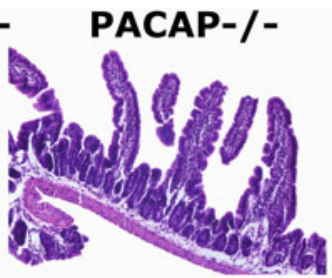

3 hs warm I/R

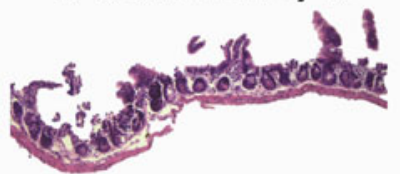

6 hs warm I/R
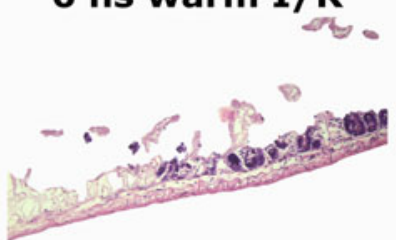

3 hs cold storage

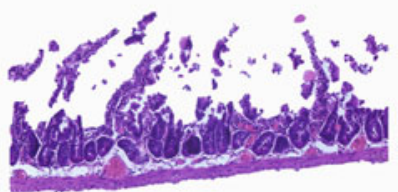

6 hs cold storage

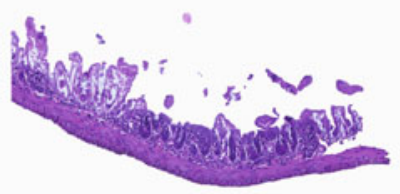

Fig. 17.2 Representative photomicrographs of small bowel sections from young adult $\mathrm{PACAP}^{+/+}$, $\mathrm{PACAP}^{+/-}$, and PACAP ${ }^{-/-}$mice. Tissue injury of small bowel after 3 and $6 \mathrm{~h}$ warm I/R and $3 \mathrm{~h}$ and $6 \mathrm{~h}$ cold preservation in $\mathrm{UW}$ in $\mathrm{PACAP}^{+/+}$and in $\mathrm{PACAP}^{-/-}$mice (Hematoxylin and eosin staining). $P A C A P^{+/+}$: PACAP wild type mice, $P A C A P^{-/-}$: PACAP knockout mice, $P A C A P^{+/-}$: PACAP heterozygous mice

damaging effect of different harmful stimuli, is suggested. Some studies have already sought to elucidate detailed mechanisms. A proteomic analysis of PACAP $\mathrm{KO}$ mice showed that several altered proteins are involved in metabolic processes, energy homeostasis, and structural integrity [66]. ATP-synthase and tubulin beta-2A 
were expressed more strongly in PACAP KO mice. In contrast, the expression of more peptides/proteins markedly decreased in $\mathrm{KO}$ mice, like pyruvate kinase, fructose biphosphate aldolase-A, glutathione S-transferase, peptidyl propyl cis-trans isomerase-A, gamma enolase, and aspartate amino transferase. The altered expression of these enzymes might partially account for the decreased antioxidant and detoxifying capacity of PACAP-deficient mice accompanying the increased vulnerability of these animals [66]. Increased proinflammatory status of neurons has also been reported in the background of increased vulnerability of PACAP KO mice [67].

\section{Effects of PACAP in Small Intestinal Inflammation}

Inflammatory bowel disease (IBD) comprises two major clinically defined types: Crohn's disease (CD) and ulcerative colitis (UC). Crohn's disease generally affects the ileum and colon, but can be present in any region of gastrointestinal tract, while ulcerative colitis is only confined to colon and rectum. Crohn's disease is often transmural and can be associated with granulomas, strictures and fistulas. On the contrary, ulcerative colitis mostly affects the mucous membrane [68]. In the next sections we discuss findings in small and large intestinal inflammation animal models and human diseases.

The occurrence and different effects of PACAP in the small intestine have been described in several species [69-73]. Regarding pathological conditions, it has been described that in atrophic rat ileum neurons expressing VIP and PACAP decrease in number [69]. Subsequent studies showed that intestinal adaptation after bypassing the distal ileum of the rat includes a transient supersensitivity of the longitudinal muscle to VIP and PACAP-27, and these augmented relaxatory responses may contribute to the hypomotility noted in inactive intestine [69]. In humans, Belai et al. [74] studied PACAP immunohistological expression in patients with Crohn's disease. They investigated the neurochemical composition of the neurons and nerve fibers of the myenteric plexus, circular smooth muscle and serosa layer of the ileal wall from nine patients with Crohn's disease and compared it with seven samples from normal controls. Increased PACAP immunoreactivity along with increased VIP and NO synthase was seen in the myenteric plexus and nerve fibers of the circular muscle layer, in the afflicted segment of Crohn's ileum. Another study on human small intestine reported a decrease of PACAP immunoreactivity along with loss of interstitial cells of Cajal in diabetic gastroenteropathy [75].

In our recent study applying a Toxoplasma gondii-induced acute ileitis model, mice were treated with PACAP38 once daily via the intraperitoneal route in two different regimens; namely, between days 1-6 postinfection (as prophylaxis) or starting on day 4 (till day 6, as therapeutic treatment), when first histopathological changes are observed in the ileal mucosa [76]. The treatment prolonged the survival of the infected mice: while all placebo-treated control mice died by day $9.5,80 \%$ of mice with PACAP prophylaxis and $40 \%$ with PACAP therapeutic treatment survived the acute phase. Twenty percent of the prophylaxis group survived till the end 
of experiment. This inflammation ameliorating (anti-inflammatory) effect of PACAP was further supported by less pronounced weight loss of treated mice, and by less distinct shrinkage of the small intestines. Histopathological examination of the ileal mucosa revealed that 7 days postinfection, placebo-treated control mice displayed severe necrosis of the mucous membrane, whereas moderate ileitis was found in the PACAP therapeutic group and only mild inflammation in the prophylaxis group. Given that PACAP did not exert direct effects on the intestinal microbiota composition, the beneficial effects are rather due to the anti-inflammatory, protective actions of the peptide as confirmed by studies of defined pro- and antiinflammatory markers. The local increase in CD3+ T cells, for instance, and the local decrease in regulatory $\mathrm{T}$ cells was less marked in the PACAP-treated groups. In addition, lower ileal neutrophils, monocytes and macrophages were observed after PACAP treatment. Furthermore, ileal expression of proinflammatory cytokines including IL-23p19 (interleukin- 23p19), IL-22 (interleukin-22), IFN-gamma (interferon gamma), and MCP-1 (monocyte chemoattractant protein-1) was reduced in ileal ex vivo biopsies derived from PACAP-treated mice. The diminished proinflammatory response upon PACAP was further underlined by lower protein concentrations of IFN-gamma and NO in ex vivo biopsies of mesenteric lymph nodes taken from PACAP-treated mice. Our results from extraintestinal compartments revealed that PACAP prophylaxis also abrogated systemic inflammatory responses, as demonstrated by the decreased level of TNF-alpha (tumor necrosis factor alpha) and $\mathrm{NO}$ (nitrogen monoxide) in the spleen and of TNF-alpha, IFN-gamma, MCP-1, and IL-6 (interleukin-6) in the liver. Higher levels of anti-inflammatory cytokines such as IL-10 and IL-4 were measured in the serum/spleen and in the liver/mesenteric lymph node, respectively, of PACAP-treated animals. Furthermore, kidney and lung histology revealed less tissue damage after PACAP prophylaxis. Altogether, these results show that both PACAP therapeutic and prophylactic treatments can reduce the symptoms and pathological signs of ileitis in a murine model by a complex mechanistic network. The prophylactic treatment resulted to be more effective (in a time-of-treatment dependent manner), and could also reduce the extraintestinal sequelae of the T. gondii induced inflammation [76].

\section{Effects of PACAP in Large Intestinal Inflammation}

Similarly to the small intestine, occurrence of PACAP and its receptors as well as different functions of PACAP have been described in the large intestine of different species, including humans [77-82]. Regarding pathological changes, only a few data are available. Gonkowski and Calka [81] reported that immunoreactive PACAP changes in different large intestinal pathologies in the pig. They found that in the porcine descending colon chemically induced inflammation, nerve injury, and proliferative enteropathy (a naturally occurring inflammation of the porcine digestive tract) resulted in an increase in the number of PACAP-27-like immunoreactive (LI) nerve fibers in the circular muscle and mucosal layers. The number of PACAP-containing 
perikarya also increased in all cases in the myenteric and submucosal plexus, except for the outer submucosal plexus in case of axotomy-induced pathology. In another study, Wojtkiewicz et al. [83] described inflammation-induced changes in the neurochemical composition of the inferior mesenteric ganglia supplying the lower portion of the colon in pigs. Although PACAP was not investigated, they found that the number of VIP immunoreactive neurons was reduced in proliferative enteropathy. Changes in PACAP and receptor expression were also demonstrated in dextran sodium sulfate (DSS)-induced colitis of mice. A marked upregulation of PACAP (and of VIP) mRNA expression was shown in TRPA1 (transient receptor potential Ankyrin type 1) KO mice, while this was not observed in wild type controls [84]. Expression levels of VPAC2 and PAC1R mRNA were not altered, whereas that of VPAC1 was downregulated in TRPA1 KO mice 10 days following colitis induction [84]. An earlier study revealed that mice lacking the TRPV-1 (transient receptor potential cation channel subfamily V member 1) receptor exhibit a defect in PACAP expression. The authors argue that this might contribute to the development of a local pro-inflammatory environment characteristic for these mice. This might also be an additional factor for colitis-associated cancer development [85].

Regarding human colonic samples, in an earlier study we found significantly lower levels of PACAP38-LI and PACAP27-LI in tumoral and peripheral samples compared with normal healthy tissue in colon cancers, similarly to some urogenital tumors [86, 87]. This observation is in accordance with immunohistochemical analysis of human sigmoid colon and rectum tumors, where a less dense PACAP immunoreactive nerve fiber network was observed in the myenteric and submucosal plexi than in normal controls [88]. Another study found that in patients with symptomatic diverticular disease significantly higher PACAP levels can be detected along with increases in other neuropeptides within the mucosal plexus. Patients with symptomatic diverticular disease exhibit increased neuropeptides in mucosal biopsies, which may reflect resolved prior inflammation, as it parallels the changes seen in acute and chronic diverticulitis [89]. In contrast, another study found decreased density of PACAP containing nerve fibers in colon mucosal membrane of children with ulcerative colitis [90, 91]. Decreased immunoreactivity (measured both by immunohistochemistry and RIA) was also observed in the aganglionic segment of human colon with Hirschsprung's disease [92].

\section{Measurement of PACAP Levels in Human Inflammatory Bowel Diseases}

Our group performed a human study to determine PACAP levels in inflammatory conditions. We examined samples taken from patients suffering from ulcerative colitis $(n=30)$ or Crohn's disease $(n=22)$ and used samples obtained from patients having diarrhea without any morphological abnormality as controls $(n=8)$, after obtaining patients' consent. In both groups of IBD 3 grades were distinguished: (1) chronic inflammation with lymphocyte and plasma cell infiltration without cryptitis or crypt abscess; (2) acute inflammation with cryptitis or crypt abscess and neutrophil 

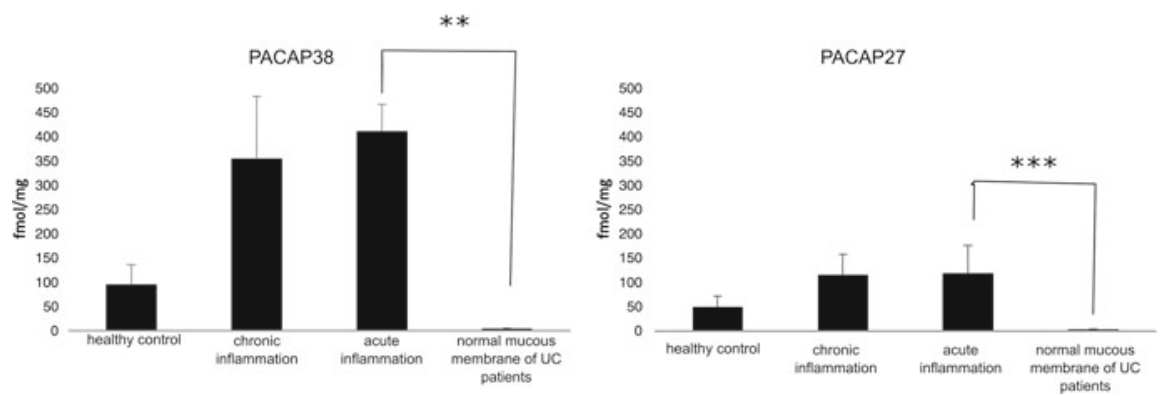

Fig. 17.3 PACAP38-like immunoreactivity (LI) and PACAP27-LI as measured by RIA in colon samples from patients suffering from ulcerative colitis. Data are expressed as mean fmol/mg tissue weight \pm SEM. $* * p<0.01 ; * * * p<0.001$

infiltration; (3) normal mucous membrane showing no signs of inflammation. For observing the effects of antibiotic therapy on PACAP level, colon samples of IBD patients treated with metronidazol or ciprofloxacin/metronidazol combination (CD: $n=5$; UC: $n=7$ ) were also examined. The procedure used was in accordance with protocols approved by the ethical committee (no. 2784,3117, University of Pecs; 8-28/92 009-10 I 8EKU, ETT TUKEB, Ministry of Health, Hungary). Tissue samples were weighed and homogenized in ice-cold distilled water. The homogenate was centrifuged $\left(12,000 \mathrm{rpm}, 4{ }^{\circ} \mathrm{C}, 30 \mathrm{~min}\right)$, and the supernatant was further processed for RIA analysis of PACAP38 and PACAP27 contents, as previously described [93, 94]. For these measurements antiserum PACAP38 "88111-3" (working dilution, 1:10,000) and PACAP27 "88123" (dilution: 1:45,000) were used.

These results show marked increase in both PACAPs' levels in ulcerative colitis (Fig. 17.3), but only a slight increase in PACAP38 could be detected in Crohn's disease (Fig. 17.4) compared to normal mucous membrane of these patients showing no inflammatory signs. We found that both PACAP38 and PACAP27 levels of normal mucous membrane samples of UC patients were much lower than in the inflamed samples, but there were no differences in case of CD patients. Measuring PACAP levels, significant elevation of both PACAPs could be detected in samples obtained from colon of UC patients showing acute inflammation. Studying the possible effect of antibiotics on PACAP levels in IBD patients revealed a significant decrease of both PACAP38 and PACAP27 level in UC patients receiving antibiotics treatment (Fig. 17.5). A moderate, but detectable decrease of PACAPs was seen in samples of CD patients.

\section{Effects of Endogenous PACAP}

The protective effects of endogenous PACAP have also been shown in mouse models of inflammatory colon diseases performed in PACAP KO mice [59]. Two groups, independently of each other and at the same time, reported similar results in DSSinduced colonic inflammation, a model of inflammatory bowel disease $[95,96]$. 


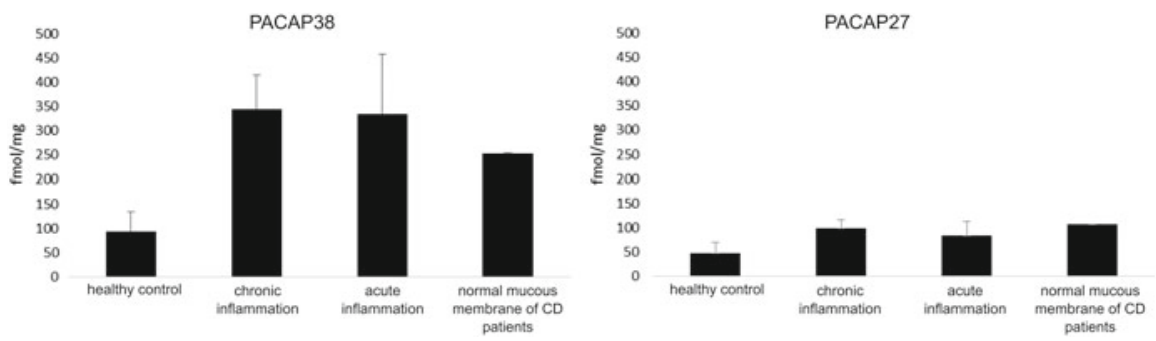

Fig. 17.4 PACAP38-LI and PACAP27-LI as measured by RIA in colon samples from patients suffering from Crohn's disease. Data are expressed as mean $\mathrm{fmol} / \mathrm{mg}$ tissue weight $\pm \mathrm{SEM}$
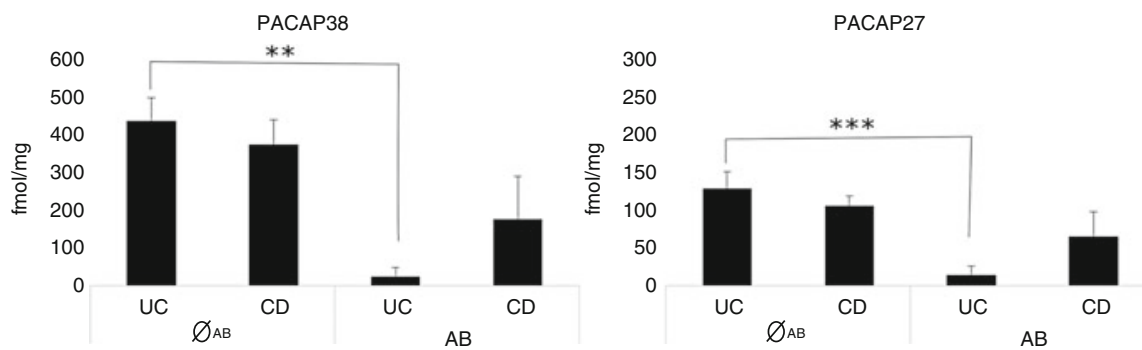

Fig. 17.5 PACAP38-LI and PACAP27-LI in IBD patients treated with antibiotics determined by RIA. Data are expressed as mean fmol/mg tissue weight \pm SEM. $* * p<0.01 ; * * * p<0.001 \mathrm{AB}$ : colon samples of patients receiving antibiotic therapy, ØAB: patients without antibiotic therapy

Azuma and coworkers [95], using a 7-day exposure (short-term) to DSS, found that PACAP KO mice exhibited higher mortality (increased by about $50 \%$ ) and increased weight loss, bleeding and diarrhea, symptoms that are used to determine the disease activity index. The large intestines were more shortened in PACAP KO mice, to one third of wild type mice. Similarly to our observations, the authors did not find morphological differences in the colonic sections in intact PACAP KO mice. However, histological scoring of the proximal and distal colon parts in DSS-induced colitis showed an increased number of infiltrating cells and crypt damage in PACAPdeficient mice. Furthermore, production of IL-1beta and IL-6 was upregulated by $50 \%$ in the proximal colon of PACAP-deficient mice, and that of IFN-gamma, IL-1beta, IL-6, IL-12, and keratinocyte-derived chemokine expression was upregulated in the distal colon by $50 \%$ [95]. Conversely, levels of anti-inflammatory cytokines such as IL-10 were only one third of that of wild type mice in the distal colon. Using a longer exposure to DSS (2 months), Nemetz and coworkers [96] described similar results. After induction of colitis by exposure to DSS, PACAP knockout animals displayed more severe clinical symptoms and higher histological inflammation scores (50-70\% higher), restricted to the distal colon. In addition, induction of IL-1beta and IL-6 mRNA expression levels were significantly higher (70\%) in PACAP-deficient mice. Interestingly, $60 \%$ of PACAP KO mice developed colorectal tumors with aggressive-appearing pathology [96]. 
As both studies showed, PACAP-deficient mice receiving normal water without DSS displayed no signs of inflammation (and of colitis), suggesting that the lack of endogenous PACAP does not result in immune depression leading to spontaneous development of colitis. This is in agreement with our own observations that mice lacking endogenous PACAP do not spontaneously develop increased inflammatory status (not shown), but based on the above-described reports, the lack of endogenous PACAP leads to increased vulnerability to inflammation and inflammationassociated cancer development in the colon.

In summary, PACAP is widely distributed in the gastrointestinal tract and exerts several different effects. Based on the studies reviewed here in detail, PACAP seems to be an important endogenous protective factor in ischemic and inflammatory bowel diseases and exogenous PACAP treatment can counteract changes in ischemic and inflammatory models. Human data indicate that PACAP levels change in inflammatory conditions the clinical relevance of which needs further investigation.

Acknowledgements This study was supported by OTKA K104984, 119759 Arimura Foundation, TAMOP 4.2.4.A/2-11-1-2012-0001 "National Excellence Program," Bolyai Scholarship of the Hungarian Academy of Sciences, PTE AOK KA Research Grant, PTE-KA 300019 and New National Excellence Program (UNKP). This work is dedicated to the 650th anniversary of the University of Pecs.

\section{References}

1. Arimura A, Somogyvari-Vigh A, Weill C, Fiore RC, Tatsuno I, Bay V, et al. PACAP functions as a neurotrophic factor. Ann N Y Acad Sci. 1994;739:228-43.

2. Somogyvari-Vigh A, Reglodi D. Pituitary adenylate cyclase activating polypeptide: a potential neuroprotective peptide. Curr Pharm Des. 2004;10:2861-89.

3. Lee EH, Seo SR. Neuroprotective roles of pituitary adenylate cyclase-activating polypeptide in neurodegenerative diseases. BMB Rep. 2014;47:369-75.

4. Reglodi D, Kiss P, Lubics A, Tamas A. Review on the protective effects of PACAP in models of neurodegenerative diseases in vitro and in vivo. Curr Pharm Des. 2011;17:962-72.

5. Shioda S, Nakamachi T. PACAP as a neuroprotective factor in ischemic neuronal injuries. Peptides. 2015;72:202-7.

6. Fujimiya M, Inui A. Peptidergic regulation of gastrointestinal motility in rodents. Peptides. 2000;21:1565-82.

7. Holmberg A, Schwerte T, Pelster B, Holmgren S. Ontogeny of the gut motility control system in zebrafish Danio rerio embryos and larvae. J Exp Biol. 2004;207:4085-94.

8. Farre R, Auli M, Lecea B, Martinez E, Clave P. Pharmacologic characterization of intrinsic mechanisms controlling tone and relaxation of porcine lower esophageal sphincter. J Pharmacol Exp Ther. 2006;316:1238-48.

9. Lindestrom LM, Ekblad E. Origins and projections of nerve fibres in rat pyloric sphincter. Auton Neurosci. 2002;97:73-82.

10. Rattan S, Chakder S. Sites of actions of contractile and relaxant effects of pituitary adenylate cyclase activating peptide (PACAP) in the internal anal sphincter smooth muscle. Ann N Y Acad Sci. 1998;865:503-11.

11. Al-Qudah M, Alkahtani R, Akbarali HI, Murthy KS, Grider JR. Stimulation of synthesis and release of brain-derived neurotropic factor from intestinal smooth muscle cells by substance $P$ and pituitary adenylate cyclase-activating peptide. Neurogastroenterol Motil. 2015;27:1162-74. 
12. Wu MJ, Kee KH, Na J, Kim SW, Bae Y, Shin DH, et al. Pituitary adenylate cyclase-activating polypeptide inhibits pacemaker activity of colonic interstitial cells of Cajal. Korean J Physiol Pharmacol. 2015;19:435-40.

13. Ferencz A, Szanto Z, Borsiczky B, Kiss K, Kalmar-Nagy K, Telek G, et al. The effects of preconditioning on the oxidative stress in small bowel autotransplantation. Surgery. 2002;132:877-84.

14. Mittal A, Phillips ARJ, Loveday B, Windsor JA. The potential role for xanthine oxidase inhibition in major intra-abdominal surgery. World J Surg. 2008;32:288-95.

15. Reglodi D, Somogyvari-Vigh A, Vigh S, Kozicz T, Arimura A. Delayed systemic administration of PACAP38 is neuroprotective in transient middle cerebral artery occlusion in rat. Stroke. 2000;31:1411-7.

16. Uchida D, Arimura A, Somogyvari-Vigh A, Shioda S, Banks WA. Prevention of ischemiainduced death of hippocampal neurons by pituitary adenylate cyclase activating polypeptide. Brain Res. 1996;736:280-6.

17. Brifault C, Gras M, Liot D, May V, Vaudry D, Wurtz O. Delayed pituitary adenylate cyclaseactivating polypeptide delivery after brain stroke improves functional recovery by inducing $\mathrm{m} 2$ microglia/macrophage polarization. Stroke. 2015;46:520-8.

18. Chen Y, Samal B, Hamelink CR, Xiang CC, Chen Y, Chen M, et al. Neuroprotection by endogenous and exogenous PACAP following stroke. Regul Pept. 2006;137:4-19.

19. Lenti L, Zimmermann A, Kis D, Olah O, Toth GK, Hegyi O, et al. PACAP and VIP differentially preserve neurovascular reactivity after global cerebral ischemia in newborn pigs. Brain Res. 2009;1283:50-7.

20. Tamas A, Reglodi D, Szanto Z, Borsiczky B, Nemeth J, Lengvari I. Comparative neuroprotective effects of preischemic PACAP and VIP administration in permanent occlusion of the middle cerebral artery in rats. Neuro Endocrinol Lett. 2002;23:249-54.

21. Atlasz T, Szabadfi K, Kiss P, Tamas A, Toth G, Reglodi D, et al. Evaluation of the protective effects of PACAP with cell-specific markers in ischemia-induced retinal degeneration. Brain Res Bull. 2010;81:497-504.

22. Danyadi B, Szabadfi K, Reglodi D, Mihalik A, Danyadi T, Kovacs Z, et al. PACAP application improves functional outcome of chronic retinal ischemic injury in rats-evidence from electroretinographic measurements. J Mol Neurosci. 2014;54:293-9.

23. Seki T, Itoh H, Nakamachi T, Endo K, Wada Y, Nakamura K, et al. Suppression of rat retinal ganglion cell death by PACAP following transient ischemia induced by high intraocular pressure. J Mol Neurosci. 2011;43:30-4.

24. Ji H, Zhang Y, Shen XD, Gao F, Huang CY, Abad C, et al. Neuropeptide PACAP in mouse liver ischemia and reperfusion injury: immunomodulation by the cAMP-PKA pathway. Hepatology. 2013;57:1225-37.

25. Horvath G, Racz B, Reglodi D, Kovacs K, Kiss P, Gallyas Jr F, et al. Effects of PACAP on mitochondrial apoptotic pathways and cytokine expression in rats subjected to renal ischemia/ reperfusion. J Mol Neurosci. 2010;42:411-8.

26. Laszlo E, Kiss P, Horvath G, Szakaly P, Tamas A, Reglodi D. The effects of pituitary adenylate cyclase-activating polypeptide in renal ischemia/reperfusion. Acta Biol Hung. 2014;65:369-78.

27. Laszlo E, Varga A, Kovacs K, Jancso G, Kiss P, Tamas A, et al. Ischemia/reperfusion-induced kidney injury in heterozygous PACAP-deficient mice. Transplant Proc. 2015;47:2210-5.

28. Szakaly P, Kiss P, Lubics A, Magyarlaki T, Tamas A, Racz B, et al. Effects of PACAP on survival and renal morphology in rats subjected to renal ischemia/reperfusion. J Mol Neurosci. 2008;36:89-96.

29. Roth E, Weber G, Kiss P, Horvath G, Toth G, Gasz B, et al. Effect of PACAP and preconditioning against ischemia/reperfusion-induced cardiomyocyte apoptosis in vitro. Ann N Y Acad Sci. 2009;1163:512-6.

30. Ferencz A, Racz B, Tamas A, Reglodi D, Lubics A, Nemeth J, et al. Influence of PACAP on oxidative stress and tissue injury following small-bowel autotransplantation. J Mol Neurosci. 2009;37:168-76. 
31. Ferencz A, Racz B, Tamas A, Nedvig K, Nemeth J, Kalmar-Nagy K, et al. Changes and effect of PACAP-38 on intestinal ischemia-reperfusion and autotransplantation. Transplant Proc. 2009;41:57-9.

32. Ferencz A, Reglodi D, Kalmar-Nagy K, Horvath OP, Roth E, Weber G, et al. Influence of pituitary adenylate cyclase-activating polypeptide on the activation of mitogen activated protein kinases following small bowel cold preservation. Transplant Proc. 2009;41:60-2.

33. Nedvig K, Weber G, Nemeth J, Kovacs K, Reglodi D, Kemeny A, et al. Changes of PACAP immunoreactivities and cytokine levels after PACAP-38 containing intestinal preservation and autotransplantation. J Mol Neurosci. 2012;48:788-94.

34. Seaborn T, Masmoudi-Kouli O, Fournier A, Vaudry H, Vaudry D. Protective effects of pituitary adenylate cyclase-activating polypeptide (PACAP) against apoptosis. Curr Pharm Des. 2011;17:204-14.

35. Brown D, Tamas A, Reglodi D, Tizabi Y. PACAP protects against inflammatory-mediated toxicity in dopaminerg SH-SY5Y cells: implication for Parkinson's disease. Neurotox Res. 2014;26:230-9.

36. Dejda A, Seaborn T, Bourgault S, Touzani O, Fournier A, Vaudry H, et al. PACAP and a novel stable analog protect rat brain from ischemia: insight into the mechanisms of action. Peptides. 2011;32:1207-16.

37. Rozzi SJ, Borelli G, Ryan K, Steiner JP, Reglodi D, Mocchetti I, et al. PACAP27 is protective against tat-induced neurotoxicity. J Mol Neurosci. 2014;54:485-93.

38. Racz B, Horvath G, Reglodi D, Gasz B, Kiss P, Gallyas Jr F, et al. PACAP ameliorates oxidative stress in the chicken inner ear: an in vitro study. Regul Pept. 2010;160:91-8.

39. Szabadfi K, Szabo A, Kiss P, Reglodi D, Setalo Jr G, Kovacs K, et al. PACAP promotes neuron survival in early experimental diabetic retinopathy. Neurochem Int. 2014;64:84-91.

40. Banki E, Kovacs K, Nagy D, Juhasz T, Degrell P, Csanaky K, et al. Molecular mechanisms underlying the nephroprotective effects of PACAP in diabetes. $\mathrm{J}$ Mol Neurosci. 2014;54:300-9.

41. Gasz B, Racz B, Roth E, Borsiczky B, Ferencz A, Tamas A, et al. Pituitary adenylate cyclaseactivating polypeptide protects cardiomyocytes against oxidative stress-induced apoptosis. Peptides. 2006;27:87-94.

42. Mori H, Nakamachi T, Ohtaki H, Yofu S, Sato A, Endo K, et al. Cardioprotective effect of endogenous pituitary adenylate cyclase-activating polypeptide on doxorubicin-induced cardiomyopathy in mice. Circ J. 2010;74:1183-90.

43. Miyamoto K, Tsumuraya T, Ohtaki H, Dohi K, Satoh K, Xu Z, et al. PACAP38 suppresses cortical damage in mice with traumatic brain injury by enhancing antioxidant activity. J Mol Neurosci. 2014;54:370-9.

44. Masmoudi-Kouki O, Douiri S, Hamdi Y, Kaddour H, Bahdoudi S, Vaudry D, et al. Pituitary adenylate cyclase-activating polypeptide protects astroglial cells against oxidative stressinduced apoptosis. J Neurochem. 2011;117:403-11.

45. Horvath G, Brubel R, Kovacs K, Reglodi D, Opper B, Ferencz A, et al. Effects of PACAP on oxidative stress-induced cell death in rat kidney and human hepatocyte cells. J Mol Neurosci. 2011;43:67-75.

46. Reglodi D, Fabian Z, Tamas A, Lubics A, Szeberenyi J, Alexy T, et al. Effects of PACAP on in vitro and in vivo neuronal cell death, platelet aggregation, and production of reactive oxygen radicals. Regul Pept. 2004;123:51-9.

47. Delgado M, Genea D. Inhibition of endotoxin-induced macrophage chemokine production by vasoactive intestinal peptide and pituitary adenylate cyclise activating polypeptide in vitro and in vivo. J Immunol. 2001;167:966-75.

48. Abad C, Waschek JA. Immunomodulatory roles of VIP and PACAP in models of multiple sclerosis. Curr Pharm Des. 2011;17:1025-35.

49. Ganea D, Rodriguez R, Delgado M. Vasoactive intestinal peptide and pituitary adenylate cyclase-activating polypeptide: players in innate and adaptive immunity. Cell Mol Biol (Noisyle-grand). 2003;49:127-42. 
50. Delgado M, Jonakait GM, Ganea D. Vasoactive intestinal peptide and pituitary adenylate cyclase-activating polypeptide inhibit chemokine production in activated microglia. Glia. 2002;39:148-61.

51. Delgado M, Leceta J, Ganea D. Vasoactive intestinal peptide and pituitary adenylate cyclaseactivating polypeptide inhibit the production of inflammatory mediators by activated microglia. J Leukoc Biol. 2003;73:155-64.

52. Wainwright DA, Xin J, Sanders VM, Jones KJ. Differential actions of pituitary adenylyl cyclase-activating polypeptide and interferon gamma on Th2- and Th1-associated chemokine expression in cultured murine microglia. J Neurodegener Regen. 2008;1:31-4.

53. Wada Y, Nakamachi T, Endo K, Seki T, Ohtaki H, Tsuchikawa D, et al. PACAP attenuates NMDA-induced retinal damage in association with modulation of the microglia/macrophage status into an acquired deactivation subtype. J Mol Neurosci. 2013;51:493-502.

54. Banki E, Degrell P, Kiss P, Kovacs K, Kemeny A, Csanaky K, et al. Effect of PACAP treatment on kidney morphology and cytokine expression in rat diabetic nephropathy. Peptides. 2013;42:125-30.

55. Szabo A, Danyadi B, Bognar E, Szabadfi K, Fabian E, Kiss P, et al. Effect of PACAP on MAP kinases, Akt and cytokine expressions in rat retinal hypoperfusion. Neurosci Lett. 2012;523:93-8.

56. Ferencz A, Weber G, Helyes Z, Hashimoto H, Baba A, Reglodi D. Presence of endogenous PACAP-38 ameliorated intestinal cold preservation tissue injury. J Mol Neurosci. 2010;42:428-34.

57. Ferencz A, Kiss P, Weber G, Helyes Z, Shintani N, Baba A, et al. Comparison of intestinal warm ischemic injury in PACAP knockout and wild-type mice. $\mathrm{J}$ Mol Neurosci. 2010;42:435-42.

58. Ferencz A, Nedvig K, Fekecs T, Racz B, Weber G, Hashimoto H, et al. Comparison of intestinal cold preservation injury on pituitary adenylate cyclase-activating polypeptide in knockout and wild-type mice. Transplant Proc. 2010;42:2290-2.

59. Reglodi D, Kiss P, Szabadfi K, Atlasz T, Gabriel R, Horvath G, et al. PACAP is an endogenous protective factor-insights from PACAP-deficient mice. J Mol Neurosci. 2012;48:482-92.

60. Ohtaki H, Nakamachi T, Dohi K, Aizawa Y, Takaki A, Hodoyama K, et al. Pituitary adenylate cyclase-activating polypeptide (PACAP) decreases ischemic neuronal cell death in association with IL-6. Proc Natl Acad Sci U S A. 2006;103:7488-93.

61. Nakamachi T, Ohtaki H, Yofu S, Dohi K, Watanabe J, Mori H, et al. Endogenous pituitary adenylate cyclase activating polypeptide is involved in suppression of edema in the ischemic brain. Acta Neurochir Suppl. 2010;106:43-6.

62. Szabadfi K, Atlasz T, Kiss P, Danyadi B, Tamas A, Helyes Z, et al. Mice deficient in pituitary adenylate cyclase-activating polypeptide (PACAP) are more susceptible to retinal ischemic injury in vivo. Neurotox Res. 2012;21:41-8.

63. Szakaly P, Laszlo E, Kovacs K, Racz B, Horvath G, Ferencz A, et al. Mice deficient in pituitary adenylate cyclase activating polypeptide (PACAP) show increased susceptibility to in vivo renal ischemia/reperfusion injury. Neuropeptides. 2011;45:113-21.

64. Elekes K, Sandor K, Moricz A, Kereskai L, Kemeny A, Szoke E, et al. Pituitary adenylate cyclase-activating polypeptide plays an anti-inflammatory role in endotoxin-induced airway inflammation: In vivo study with gene-deleted mice. Peptides. 2011;32:1439-46.

65. Kemeny A, Reglodi D, Cseharovszky R, Hashimoto H, Baba A, Szolcsanyi J, et al. Pituitary adenylate cyclase-activating polypeptide deficiency enhances oxazolone-induced allergic contact dermatitis in mice. J Mol Neurosci. 2010;42:443-9.

66. Maasz G, Pirger Z, Reglodi D, Petrovics D, Schmidt J, Kiss P, et al. Comparative protein composition of the brains of PACAP-deficient mice using mass spectrometry-based proteomic analysis. J Mol Neurosci. 2014;54:310-9.

67. Watson MB, Nobuta H, Abad C, Lee SK, Bala N, Zhu C, et al. PACAP deficiency sensitizes nigrostriatal dopaminergic neurons to paraquat-induced damage and modulates central and peripheral inflammatory activation in mice. Neuroscience. 2013;240:277-86.

68. Abraham C, Cho JH. Inflammatory bowel disease. N Engl J Med. 2009;19:2066-78. 
69. Ekelund M, Ekblad E. Intestinal adaptation in atrophic rat ileum is accompanied by supersensitivity to vasoactive intestinal peptide, pituitary adenylate cyclase-activating peptide and nitric oxide. Scand J Gastroenterol. 2001;36:251-7.

70. Lazar Z, Shahbazian A, Benko R, Toth G, Penke B, Bartho L, et al. PACAP-(6-38) inhibits the effects of vasoactive intestinal polypeptide, but not PACAP, on the small intestinal circular muscle. Eur J Pharmacol. 2001;431:259-64.

71. Mao YK, Wang YF, Moogk C, Fox-Threlkeld JE, Xiao Q, McDonald TJ, et al. Locations and molecular forms of PACAP and sites and characteristics of PACAP receptors in canine ileum. Am J Physiol. 1998;274:G217-25.

72. Pirone A, Baoan D, Piano I, Della Santina L, Baglini A, Lenzi C. Pituitary adenylate cyclaseactivating peptide (PACAP) immunoreactivity distribution in the small intestine of the adult New Hampshire chicken. Acta Histochem. 2011;113:477-83.

73. Zizzo MG, Mulé F, Serio R. Mechanisms underlying the inhibitory effects induced by pituitary adenylate cyclase-activating peptide in mouse ileum. Eur J Pharmacol. 2005;521:133-8.

74. Belai A, Boulos PB, Robson T, Burnstock G. Neurochemical coding in the small intestine of patients with Crohn's disease. Gut. 1997;40:767-74.

75. He CL, Soffer EE, Ferris CD, Walsh RM, Szurszewski JH, Farrugia G. Loss of interstitial cells of cajal and inhibitory innervation in insulin-dependent diabetes. Gastroenterology. 2001;121:427-34.

76. Heimesaat MM, Dunay IR, Schulze S, Fischer A, Grundmann U, Alutis M, et al. Pituitary adenylate cyclase-activating polypeptide ameliorates experimental acute ileitis and extraintestinal sequelae. PLoS One. 2014;9:e108389.

77. Leung PS, So SC, Lam SY, Tsang LL, Chung YW, Chan HC. Local regulation of anion secretion by pituitary adenylate cyclase-activating polypeptide in human colonic T84 cells. Cell Biol Int. 2001;25:123-9.

78. Rettenbacher M, Reubi JC. Localization and characterization of neuropeptide receptors in human colon. Naunyn Schmiedebergs Arch Pharmacol. 2001;364:291-304.

79. Miampamba M, Germano PM, Arli S, Wong HH, Scott D, Tache Y, et al. Expression of pituitary adenylate cyclase-activating polypeptide and PACAP type 1 receptor in the rat gastric and colonic myenteric neurons. Regul Pept. 2002;105:145-54.

80. Uyttebroek L, Shepherd IT, Harrisson F, Hubens G, Blust R, Timmermans JP, et al. Neurochemical coding of enteric neurons in adult and embryonic zebrafish (Danio rerio). Cancer Res. 2012;72:1705-16.

81. Gonkowski S, Calka J. Changes in pituitary adenylate cyclase-activating peptide 27-like immunoreactive nervous structures in the porcine descending colon during selected pathological processes. J Mol Neurosci. 2012;48:777-87.

82. Gonkowski S, Kaminska B, Landowski P, Calka J. Immunohistochemical distribution of cocaine- and amphetamine-regulated transcript peptide-like immunoreactive (CART-LI) nerve fibers and various degree of co-localization with other neuronal factors in the circular muscle layer of human descending colon. Histol Histopathol. 2013;28:851-8.

83. Wojtkiewicz J, Rowniak M, Gonkowski S, Crayton R, Majewski M, Robak A, et al. Proliferative enteropathy (PE)-induced changes in the calbindin-immunoreactive (CB-IR) neurons of inferior mesenteric ganglion supplying the descending colon in the pig. $\mathrm{J}$ Mol Neurosci. 2012;48:757-65.

84. Kun J, Szitter I, Kemeny A, Perkecz A, Kereskai L, Pohoczky K, et al. Upregulation of the transient receptor potential ankyrin 1 ion channel in the inflamed human and mouse colon and its protective roles. PLoS One. 2014;9:e108164.

85. Vinuesa AG, Sancho R, Garcia-Limones C, Behrens A, Ten Dijke P, Calzado MA, et al. Vanilloid receptor-1 regulates neurogenic inflammation in colon and protects mice from colon cancer. J Comp Neurol. 2010;518:4419-38.

86. Szanto Z, Sarszegi Z, Reglodi D, Nemeth J, Szabadfi K, Kiss P, et al. PACAP immunoreactivity in human malignant tumor samples and cardiac diseases. J Mol Neurosci. 2012;48:667-73.

87. Tamas A, Javorhazy A, Reglodi D, Sarlos DP, Banyai D, Semjen D, et al. Examination of PACAP-like immunoreactivity in urogenital tumor samples. J Mol Neurosci. 2016;59:177-83. 
88. Godlewski J, Lakomy IM. Changes in vasoactive intestinal peptide, pituitary adenylate cyclaseactivating polypeptide and neuropeptide Y-ergic structures of the enteric nervous system in the carcinoma of the human large intestine. Folia Histochem Cytobiol. 2010;48:208-16.

89. Simpson J, Sundler F, Humes DJ, Jenkins D, Scholefield JH, Spiller RC. Post inflammatory damage to the enteric nervous system in diverticular disease and its relationship to symptoms. Neurogastroenterol Motil. 2009;21:847-e58.

90. Kaminska B, Landowski P, Gonkowski S, Majewski M, Renke J, Korzon M. Changes in the number of neuroprotective transmitter containing mucosal nerve fibres in children with ulcerative colitis. Med Wieku Rozwoj. 2006;10:483-91.

91. Kaminska B, Landowski P, Gonkowski S, Szlagatys-Sidorkiewitz A, Majewski M, Dobosz M, et al. Analysis of enteral nervous system in children with drug resistant ulcerative colitis. Med Wieku Rozwoj. 2007;11:117-22.

92. Shen Z, Larsson LT, Malmfors G, Absood A, Håkanson R, Sundler F. A novel neuropeptide, pituitary adenylate cyclase-activating polypeptide (PACAP), in human intestine: evidence for reduced content in Hirschsprung's disease. Cell Tissue Res. 1992;269:369-74.

93. Jakab B, Reglodi D, Jozsa R, Hollosy T, Tamas A, Lubics A, et al. Distribution of PACAP-38 in the central nervous system of various species determined by a novel radioimmunoassay. J Biochem Biophys Methods. 2004;61:189-98.

94. Nemeth J, Jakab B, Jozsa R, Hollosy T, Tamas A, Lubics A, et al. PACAP-27 radioimmunoassay: description and application of a novel method. J Radioanal Nucl Chem. 2007;273:327-32.

95. Azuma YT, Hagi K, Shintani N, Kuwamura M, Nakajima H, Hashimoto H, et al. PACAP provides colonic protection against dextran sodium sulfate induced colitis. J Cell Physiol. 2008;216:111-9.

96. Nemetz N, Abad C, Lawson G, Nobuta H, Chhith S, Doung L, et al. Induction of colitis and rapid development of colorectal tumors in mice deficient in the neuropeptide PACAP. Int J Cancer. 2008;122:1803-9. 